\title{
The 'evil arrow' myths and misconceptions of cancer at Lagos University Teaching Hospital, Nigeria
}

\begin{tabular}{|c|c|}
\hline \multicolumn{2}{|c|}{$\begin{array}{l}\text { Authors: } \\
\text { Kehinde O. Ololade }^{1} \\
\text { Adewumi Alabi }^{2} \\
\text { Babatunde Fadipe }^{3} \\
\text { Bolanle Adegboyega }^{2}\end{array}$} \\
\hline \multicolumn{2}{|c|}{$\begin{array}{l}\text { Affiliations: } \\
{ }^{1} \text { Department of Radiation } \\
\text { Biology, Radiotherapy, } \\
\text { Radiodiagnosis and } \\
\text { Radiography, College of } \\
\text { Medicine, University of } \\
\text { Lagos, Nigeria }\end{array}$} \\
\hline \multicolumn{2}{|c|}{$\begin{array}{l}\text { Department of } \\
\text { Radiotherapy, Lagos } \\
\text { University Teaching Hospital, } \\
\text { Nigeria }\end{array}$} \\
\hline \multicolumn{2}{|c|}{$\begin{array}{l}{ }^{3} \text { Department of Psychiatry, } \\
\text { Lagos University Teaching } \\
\text { Hospital, Nigeria }\end{array}$} \\
\hline \multicolumn{2}{|c|}{$\begin{array}{l}\text { Corresponding author: } \\
\text { Kehinde Ololade, } \\
\text { ololadekehinde@yahoo.com }\end{array}$} \\
\hline \multicolumn{2}{|c|}{$\begin{array}{l}\text { Dates: } \\
\text { Received: } 05 \text { July } 2018 \\
\text { Accepted: } 06 \text { Nov. } 2018 \\
\text { Published: } 23 \text { Jan. } 2019\end{array}$} \\
\hline \multicolumn{2}{|c|}{$\begin{array}{l}\text { How to cite this article: } \\
\text { Ololade KO, Alabi A, Fadipe B, } \\
\text { Adegboyega B. The 'evil } \\
\text { arrow' myths and } \\
\text { misconceptions of cancer at } \\
\text { Lagos University Teaching } \\
\text { Hospital, Nigeria. S. Afr. j. } \\
\text { oncol. 2019;3(0), a49. } \\
\text { https://doi.org/10.4102/sajo. } \\
\text { v3i0.49 }\end{array}$} \\
\hline \multicolumn{2}{|c|}{$\begin{array}{l}\text { Copyright: } \\
\text { ( ) 2019. The Authors } \\
\text { Licensee: AOSIS. This } \\
\text { is licensed under the } \\
\text { Creative Commons } \\
\text { Attribution License. }\end{array}$} \\
\hline \multicolumn{2}{|l|}{ Read online: } \\
\hline 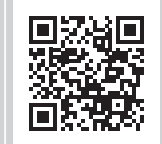 & $\begin{array}{l}\text { Scan this QR } \\
\text { code with your } \\
\text { smart phone or } \\
\text { mobile device } \\
\text { to read online. }\end{array}$ \\
\hline
\end{tabular}

Background: Myths and misconceptions have significant impact on the presentation and management of cancers globally. One such example includes 'evil arrow' myths. There is limited knowledge regarding the role of misconceptions in late presentation for management in developing countries. The percentage increase in cancers in many African countries is higher than that in developed countries. Evil arrow is the seeming attack of the enemy in a supernatural version as a result of wizardry.

Aim: To evaluate the relationship of common myths and misconceptions among cancer patients, their treatment and delay of presentation to the hospital.

Setting: The study was undertaken in a tertiary health facility in a cosmopolitan tropical state.

Method: This is a randomised observational survey study carried out among patients and their relatives referred to the Radiotherapy Clinic of the Lagos University Teaching Hospital for treatment (a lower-income mixed metropolitan setting). A self-administered questionnaire was used. Patient consent was obtained. Data were analysed with Epi Info 2002 software and the results were presented using frequency tables and charts.

Results: About 57 were patients (67\%) and 28 were patients' relatives $(33 \%)$. The age distribution of participants showed $31-40$ years $(31.8 \%$; 27$)$ as the highest number, while $11-20$ years $(1.2 \% ; 1)$ was the lowest number. A slight female preponderance of $58.8 \%$ (50) was observed. High incidence of those with the opinion that cause of cancer is unknown represented $63 \%$ (54). Over $65 \%$ of patients presented with advanced disease. The reasons for late presentation to the hospital included lack of funds in $23.5 \%$ of patients (20).

Conclusion: Lack of funds, myths and misconception are main reasons why patients presented late to hospital. There is a need to emphasise debunking innumerable myths and misconceptions associated with cancer.

\section{Introduction}

Myths and misconceptions have had significant impact on the presentation and management of cancers worldwide, particularly in African countries where cancer patients are excluded from society and have poor emotional support. ${ }^{1}$ Among such in our society are the 'evil arrow' myths. There is limited knowledge regarding the role of misconceptions in late presentation for management in developing countries. Cancer incidence, morbidity and mortality are still on the rise; worldwide cancer statistics estimated 14.1 million new cancer cases and 8.2 million cancerrelated deaths in 2012. ${ }^{2}$ It has been predicted that there would be a substantive increase to 19.3 million new cancer cases per year by 2025 because of growth and ageing of the global population. ${ }^{2}$ More than half of all cancers (56.8\%) and cancer deaths (64.9\%) in 2012 occurred in less developed regions of the world, and these proportions have been indicated to increase further by $2025 .{ }^{2}$ The percentage of higher increase in cancer in many African countries compared to developed countries can be attributed to the lack of awareness about the risk factors and changes in lifestyle. ${ }^{3}$

Evil arrow is a synonym of the seeming attack of the enemy in a supernatural version. It is thought to be as a result of wizardry. It shares a similar meaning with the 'evil eye' as noted by Kishore et al. in India. ${ }^{4}$ The relevance of this is to help understand how patients in developing countries accept their condition as either a victim of the evil arrow or a mere disease with an unknown cause; a similar view was shared by Modiddo et al. in his study on stigma and health-seeking behaviour in sub-Saharan Africa.,

There is still a major role that education has to play in placing emphasis on these myths and misconceptions. In India, a study by Kishore et al. demonstrated that the majority of the people 
thought that cancer was because of curse, evil eye or as a result of past $\sin .{ }^{4}$ However, some myths are actually related to the known risk factors of some specific cancers like lifestyle-related disease; an example is in Ethiopia where in some communities exposure to sunlight, which may result in melanoma, may be seen as a treatment leading to cure of malignancy. ${ }^{1}$ Information-seeking behaviour of the cancer patients as a means to cope with the stress of the diagnosis was noted by Der Molem. ${ }^{7}$ He also averred that the stigma was more pronounced among the older generation.

A perception common in our society is that cancer was contagious and may be because of past sins of an individual; for example, one patient was denied the privilege of carrying her grandchild because of the diagnosis of malignancy with the impression that the baby could contract cancer if carried by the diseased person. The role played by factors like: finances, 'point of first visit', which individual patients shared their 'condition' with and reasons for delayed presentation, vis-à-vis impact on the myths and misconceptions of cancer patients echo the findings by Daher. ${ }^{6}$ He demonstrated a couple of factors which had direct effect on the increase in the myths and misconceptions, including silencing effect of such on early health-seeking behaviour. ${ }^{8}$ Some patients experienced stigma, shame and blame as though they deliberately wanted to be cancer diseased. Chapple et al.' ${ }^{9}$ intent is to attempt to elicit the fear or otherwise of the assertion.

The aim of this study was to evaluate the relationship of common myths and misconceptions among cancer patients treated and the delay of presentation to the hospital.

\section{Materials and methods}

This is a randomised, observational survey carried out among patients and their relatives referred to the radiotherapy department for treatment in March 2012. While they were waiting for their appointment at the outpatient clinic, contact was established with the respondents and a self-administered questionnaire was used to get their views: sociodemographics, perception of the disease, self-reported stage of the disease (whether early or late), time of presentation in the hospital, impact of the diagnosis on their career, place of residence and their support system. Closed questions were used to provoke the responses and they were informed by findings of previously conducted studies, ${ }^{4,6,9}$ which aimed to assess the impact and veracity of myths on the patient. Verbal consent was obtained from all the respondents in the study prior to administering the questionnaire. They were assured that their participation was voluntary and would not interfere with their treatment at the clinic. They were informed that the data would be handled in a confidential manner and that their names would not be used in any publication or presentation. The data obtained were analysed using Epi Info 2002 software (Windows version 3.5.1) via quantitative data entry and the results were presented using frequency tables and charts.

\section{Ethical considerations}

Ethical clearance to conduct the study was obtained from Lagos University Teaching Hospital, Health Research Ethics Committee, reference number: ADM/DCST/HREC/1660.

\section{Results}

A population of 105 respondents were randomly sampled. Only 20 patients did not complete the questionnaire session. Of these, 57 were patients (67\%) and 28 were patients' relatives $(33 \%)$. The age distribution showed $31-40$ years $(31.8 \% ; 27)$ as the highest number, while $11-20$ years $(1.2 \% ; 1)$ was the lowest number. A slight female preponderance of $58.8 \%$ (50) was observed (see Table 1).

From Figure 1, it is clear that the majority $(57.6 \% ; 49)$ of participants responded that their family members are paying for the cost of their treatment, while $9.4 \%$ (8) mentioned nongovernmental or religious organisations, philanthropists, employers, etc., paying for their treatment. Almost 32.9\% (28) of participants reported to be self-paying.

Early stage of the disease accounted for $35 \%$ of cases, while the remaining $65 \%$ are in the delayed advanced stage.

TABLE 1: Socio-demographics of respondents.

\begin{tabular}{lcc}
\hline Variable & Frequency $(\boldsymbol{n}=\mathbf{8 5})$ & Percentage $\mathbf{( \% )}$ \\
\hline Age & 1 & \\
$11-20$ years & 0 & 1.2 \\
$21-30$ years & 27 & 0.0 \\
$31-40$ years & 20 & 31.8 \\
$41-50$ years & 13 & 23.5 \\
$51-60$ years & 9 & 15.3 \\
$61-70$ years & 15 & 10.6 \\
$>70$ years & & 17.6 \\
Sex & 50 & \\
Female & 35 & 58.8 \\
Male & & 41.2 \\
\hline
\end{tabular}

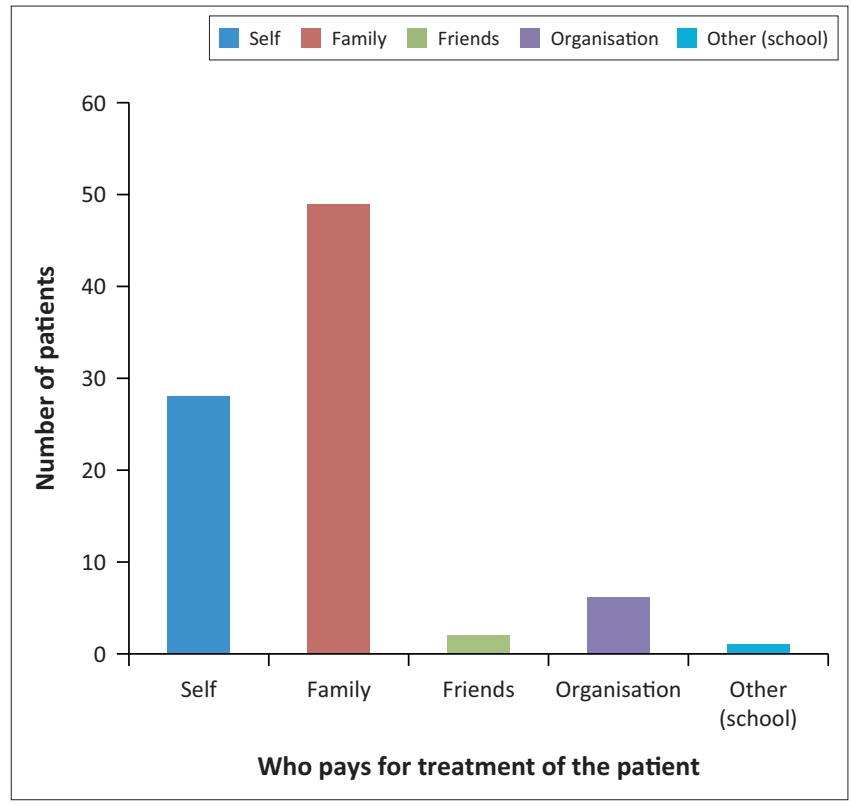

FIGURE 1: Respondents' response on who pays for their treatment. 
TABLE 2: Respondents' response to 'point of first visit'.

\begin{tabular}{lcc}
\hline Reasons & $\begin{array}{c}\text { Number of respondents } \\
\text { (57 patients) }\end{array}$ & Percentage (\%) \\
\hline Health facility & 31 & 54.4 \\
Church & 17 & 29.8 \\
Herbalist & 6 & 10.5 \\
Mosque & 3 & 5.3 \\
\hline
\end{tabular}

TABLE 3: Respondents' response to causes of cancer.

\begin{tabular}{lcc}
\hline Reasons & $\begin{array}{c}\text { Number of respondents } \\
\text { (57 patients) }\end{array}$ & Percentage (\%) \\
\hline Unknown & 54 & 63 \\
Evil arrow & 12 & 14.1 \\
Infection & 14 & 16.5 \\
Food & 11 & 12.9 \\
\hline
\end{tabular}

TABLE 4: Reasons for late presentation to hospital.

\begin{tabular}{lcc}
\hline Reasons & $\begin{array}{c}\text { Number of respondents } \\
\text { (57 patients) }\end{array}$ & Percentage (\%) \\
\hline Lack of funds & 20 & 23.5 \\
Hospital delays & 14 & 16.5 \\
Do not know what to do & 11 & 12.9 \\
Long distance to hospital & 11 & 12.9 \\
\hline
\end{tabular}

The majority of patients could tell their family members about their condition $(70.2 \%$; 40 ), while $21.1 \%$ (12) informed their religious leaders (pastor/imam) and 14\% (8) to their friends.

The majority $(54.4 \% ; 31)$ of the patients first presented to a health facility. The remainder is accounted for by those who visited churches $(29.8 \%$; 17), herbalists $(10.5 \% ; 6)$ and mosques $(5.3 \% ; 3)$ (see Table 2$)$. There was a high incidence $(63 \% ; 54)$ of those who were of the opinion that the cause of cancer is unknown. Only $14.1 \%$ (12) believed that cancer arises from evil arrow, while $16.5 \%$ (14) believed it is a result of infection and $12.9 \%$ (11) opined that it is caused from what you eat (see Table 3). The reasons for late presentation to the hospital ranged from lack of funds $(23.5 \%$; 20$)$, hospital delays $(16.5 \% ; 14)$, not knowing what to do $(12.9 \% ; 11)$ and long distance from place of residence $(12.9 \%$; 11$)$ (see Table 4 ). It is noteworthy that the majority of patients who could pay for their medical treatment did not see distance or the myths as a barrier to obtain their treatment. There is a large level of illiteracy noted among the patients, close to one-third of the population, with less than half having completed one form of higher education.

Finally, it is important to note that a majority of patients interacted with $(35.3 \%$; 30) reported that they first heard of cancer via the television, while $7.1 \%$ (6) patients said they read it in the newspaper and $7.1 \%$ (6) reported to have heard it first from friends. Those who heard of cancer for the first time in the hospital accounted for $21.2 \%$.

\section{Discussion}

The results of this study revealed that several hypotheses are associated with the cause of cancer, among which are the evil arrow myths and misconceptions seen in low socio-economic countries owing to several socio-cultural and religious beliefs. $4,6,7,9,10$ Noteworthy is the proportion of patients who feels that it emanates from evil arrow $(16.5 \% ; 14)$, the meaning of which, as reported in this study, is being ascribed to the effect of the supernatural powers on the health of an individual. A study by Modibbo et al. in Nigeria also reported that women believed that wizardry, multiple sexual partners and inserting herbs into the vagina cause cervical cancer. ${ }^{5}$ The respondents also demonstrated their beliefs that cancer can be caused by infection $(16.5 \% ; 14)$ and what you eat $(12.9 \% ; 11)$. This aligns well with the results of our survey of the challenges of cultural practices and beliefs and ascertains our view of the impact of cultural practices on the delayed orthodox medical treatment of cancers in our society.

Song $\mathrm{Wu}$ et al., while applying several distinct modelling approaches, were able to provide strong evidence that unavoidable intrinsic risk factors contribute only modestly $(<10-30 \%)$ to the development of many common cancers while contributions from extrinsic factors were not quantifiable in cancer development. They concluded that cancer risk is heavily influenced by extrinsic factors, ${ }^{11}$ while among veterans with colorectal cancer, Phelan et al. and Cho et al. in Korea noted stigma and self-blame as critical factors in a significant minority of men with colorectal cancer (CRC), independent predictors of depressive symptoms and an important source of stress in men with CRC. ${ }^{8,12}$

The age distribution showed 31-40 years age group (31.8\%; 27 ) as the highest respondent number. A slight female preponderance of $58.8 \%$ (50) was noted.

There is also the myth that mastectomy is a must for all breast cancer patients, which results in late presentation owing to the fear of mastectomy as reported by Ajekigbe et al. ${ }^{13}$ Other factors contributing to late presentation were lack of funds $(23.5 \%$; 20$)$, frequent hospital delays $(16.5 \% ; 14)$, not knowing what to do $(12.9 \% ; 11)$ and long distance from residence to hospital $(12.9 \%$; 11$)$.

Individuals who respondents were able to share their diagnosis with also demonstrated the kind of support they will benefit from and the subtle effect it may have on their health-seeking behaviour, particularly as stigma is concerned. The probability of stigmatisation played a role in the liberty with which the respondents told people about their diagnosis, which was in congruence with the findings of Cho et al., ${ }^{12}$ where more patients with cancers were prone to depression from the stigmatisation compared to the general populace.

Patients seek various forms of treatment before, during and after orthodox medicine, as reported in several African studies. Binka et al. in a Ghanaian study ${ }^{14}$ reported that patients employed numerous active and avoidant strategies to cope with their condition. A similar outlook was observed in our research where the majority of respondents (more than $60 \%$ ) demonstrated seeking remedies in at least one or more than one non-medical domains (either with the pastor, imam or traditionalist). In an attempt to cope, some tried to forget about the condition while some others denied the existence 
of the disease, knowing that it was a possible way of coping with the excruciating effects of the disease. This was reflected in their health-seeking behaviour where many of them engaged in various methods, including orthodox medicine and herbal medicine. ${ }^{14}$ In another study, breast cancer and cervical cancer patients resorted to positive thinking and purposeful lifestyle as a coping mechanism. ${ }^{15}$ In this study, there was a remarkable first-time presentation in the hospital $(93 \% ; 78)$ although this dropped sharply once diagnosis was made $(31.7 \% ; 27)$. The remainder is accounted for by those who chose to visit churches $(42.4 \%$; 36$)$, herbalists $(7.1 \%$; 6$)$ and mosque $(3.5 \% ; 3)$ as a means of dealing with the disease to achieve cure. A larger percentage of the respondents had advanced disease, a correlation that the myths of blame and shame are silencing patients and making early health-seeking behaviour difficult, is buttressed by the shame blame as noted by Chapple et al. ${ }^{9}$

Is it cheaper to be seen in the churches and to the herbalists than to be taken to the hospital? This question will be the focus of a follow-up study. This study did not demonstrate a definite comparison of the cost of the treatment in the various places as mentioned. However, an indirect inference can be made through the fact that those who had their treatment funded by their employers had a less likelihood of patient default than those who had no institutional financial support and thus had to pay out of pocket. Adoga et al. in a study conducted in northern Nigeria also reported that lack of funds was a reason for late presentation. ${ }^{16}$ In our study, the issues of financing of the therapy were among the external factors other than the cultural beliefs; those who were supported by the organisations were markedly fewer (7\%) compared with the over $60 \%$ who were funded by self or their immediate family members.

The majority of patients in our society, especially those in rural areas, lack the financial means to access modern health facilities owing to high poverty level and hence the preference for traditional beliefs and practices that make them visit the herbalists and religious homes that is affordable. Noteworthy is the small number of those who have their treatment bill covered by either a medical insurance or their employers. Those who have their employers paying are more likely to present early and to the orthodox clinic and not to the traditional healer; they also make up the higher number of those who completed treatment. Some of our patients have had to sell off their property to afford proper treatment like surgery, chemotherapy and radiotherapy. Many $(32.9 \% ; 28)$ of the patients were responsible for financing their health bills, in which case the disease would be in more advanced stages at the time of presentation as a result of the delay in raising funds. This will incur additional expenses and eventually lead to poor outcome in management. Espina et al. also affirmed that the major reason for the delay in their meta-analysis of causes of delay in seeking treatment was the socio-economic patient factors, which points to limited financing and the attendant effect on cancer care in the African sub-region. ${ }^{17}$
Among the notable factors that increase the myth is the very high cost of managing a case of malignancy. The level of poverty also encourages the visit to cheaper alternatives like herbalists and other local alternative medicine care givers. The impact played by limited resources in the acceptance of traditional healing and search for alternative treatment patterns is also noteworthy.

Who bears the cost of treatment also reflects that the family is accountable for $57.6 \%$ (49) of cases, the patient for $32.9 \%$ (28) of cases and the organisational sponsor accounting for only $7.1 \%$ (6) of cases. The employers though very supportive did not transcend to financial support, as shown by the smaller percentage $(7.1 \% ; 6)$. We noted that they could give permission for the workers to be away for treatment; however, less than half of them were actually able to financially support the staff through the period. Some actually gave the staff leave without pay and encouraged the staff to present for work whenever they are fit to continue their work routine. The financial impact of cancer management mandates mobilisation of scarce family's resources to meet the need for treatment. The family plays a major role around which African kinship groupings are organised and it is the most important social unit for people in Tanzania and across Africa with regard to treatment of chronic diseases, which is also reflected in this study. ${ }^{18}$ Consequently, living with cancer or caring for someone with cancer is very much a family matter in an African context. This affirms the need for government and improved health financing for cancer care. The participants expressed a variety of responses for the best appropriate treatment for cancers. Thirty-eight (44.7\%) patients mentioned radiotherapy as the best treatment, $28.3 \%$ (24) mentioned prayers, 25.8\% (22) mentioned chemotherapy and $21.2 \%$ (18) mentioned surgery.

About half of the respondents $(47 \% ; 40)$ could tell their family members about their diagnosis, both the symptoms and the diagnosis of cancer, $14.1 \%$ (12) to their pastor or imam and $9.4 \%$ (8) to their friends. There were also those who would rather not share their diagnosis with anyone; for example, one patient insisted that till death her diagnosis should not be revealed to anyone.

Generality of the respondents displayed the understanding of the evil arrow and this was clearly in line with the findings of the previous study by Kishore et al., ${ }^{4}$ who stated that the majority of the people thought that cancer was because of curse, evil eye or as a result of past sin. This elicits that not only in sub-Saharan Africa but also in Asia there could be misconceptions about the cause of cancer. This was also observed by Akuoko, who identified the belief of evil spirits as a cause of disease to show a reason for delayed healthseeking behaviour of patients. ${ }^{10}$ Thus, evil arrow is a pseudonym to infer the effect of metaphysical powers or the evil spirits on the health of the cancer patient.

Finally, it is important to note that the majority of patients $(35.3 \%$; 30) interacted with reported that they first heard 
about cancer via the television, while $7.1 \%$ (6) patients reported to have read it in the newspaper and $7.1 \%$ (6) reported they heard it first from their friends. Those who heard about cancer for the first time in the hospital accounted for $21.2 \%$ (18). The most common means of hearing about the disease was through the mass media and at health talks from healthcare workers in hospitals, and this is similar to the findings from other studies carried out in Nigeria and Ethiopia. ${ }^{19,20}$ It is pertinent to fast-track public education on cancer, with deliberate intention to raise awareness about the disease and correct issues of stigmatisation. This will also encourage increased early presentation at cancer clinics.

The strengths of our study include the identification of the possible effects of the myths on the health-seeking behaviour of patients, the pivotal role of financing in care seeking of cancer patients, and the need to improve on cancer awareness drives.

The limitations of our study include the possibility that the respondents may have given answers which they perceived to be more 'socially acceptable'. The respondents in this study were those who could essentially answer questions on their own and they may have provided responses that cannot be generalised to the general population with little or no formal education. Another limitation of the study is the sample size; although we conducted the study in a centre that attracts patients from all over the country, we acknowledge that our findings could be better represented with an increased sample size involving other geopolitical zones and multiple centres in the country. It is our plan to explore this further in a population-based survey.

\section{Conclusion}

'Evil arrow' as well as other myths and misconceptions encourages significant delay in medical care-seeking behaviours of cancer patients, particularly presenting to the hospital. Poverty was a significant reason why patients presented late to the hospital. Cancer is a disease where myth and misconception can facilitate the delay in seeking appropriate care or rather make patients seek wrong care. Although the cause of cancer is still a dilemma, cancer research has played a significant role in fighting the disease. There is a need to emphasise debunking innumerable myths and misconceptions associated with cancer. Concerted efforts should be geared towards addressing the numerous myths and misconceptions among the vastly poor and illiterate population in sub-Saharan Africa. The use of local language to disseminate awareness and engagements with traditional community leaders should be vigorously pursued. This research shows the need for policymakers and healthcare providers to be aware of the effect of myths and the need to foster public education programmes, community resource education, collaboration with religious leaders and herbalists, and general insight into patterns of health-seeking behaviours of patients in a low and middle income (LMIC) African country.

\section{Acknowledgements Competing interests}

The authors declare that they have no financial or personal relationships that may have inappropriately influenced them in writing this article.

\section{Authors' contributions}

K.O.O. and A.A. contributed to the design and analysis of data discussion. B.F. and B.A. contributed to the analysis of data discussion.

\section{References}

1. Birhanu Z, Abdissa A, Belachew T, et al. Health seeking behavior for cervical cancer in Ethiopia: A qualitative study. Int J Equity Health. 2012;11(1):83. https://doi. org/10.1186/1475-9276-11-83

2. Ferlay J, Soerjomataram I, Dikshit R, et al. Cancer incidence and mortality worldwide: Sources, methods and major patterns in GLOBOCAN 2012. Int Cancer. 2015;136(5):E359-86. https://doi.org/10.1002/ijc.29210

3. Siegel RL, Miller KD, Jemal A. Cancer statistics, 2016. CA Cancer J Clin. 2016;66(1):7-30. https://doi.org/10.3322/caac.21332

4. Kishore J, Ahmad I, Kaur R, Mohanta PK. Beliefs and perceptions about cancers among patients attending radiotherapy OPD in Delhi, India. Asian Pac J Cancer Prev. 2008;9(1):155-8.

5. Modibbo Fl, Dareng E, Bamisaye $\mathrm{P}$, et al. Qualitative study of barriers to cervical cancer screening among Nigerian women. BMJ Open. 2016:6(1):e008533. https:// doi.org/10.1136/bmjopen-2015-008533

6. Daher M. Cultural beliefs and values in cancer patients. Ann Oncol. 2012;23(Suppl 3): 66-9. https://doi.org/10.1093/annonc/mds091

7. Der Molem V. Relating information needs to the cancer experience: 1 . Information as a key coping strategy. Eur J Cancer Care (Engl). 1999;8(4):238-44. https://doi. org/10.1046/j.1365-2354.1999.00176.x

8. Phelan SM, Griffin JM, Jackson GL, et al. Stigma, perceived blame, self-blame, and depressive symptoms in men with colorectal cancer. Psychooncology. 2013;22(1):65-73. https://doi.org/10.1002/pon.2048

9. Chapple A, Ziebland S, McPherson A. Stigma, shame, and blame experienced by patients with lung cancer: Qualitative study. BMJ. 2004;328(7454):1470. https:// doi.org/10.1136/bmj.38111.639734.7C

10. Akuoko CP, Armah E, Sarpong T, Quansah DY, Amankwaa I, Boateng D. Barriers to early presentation and diagnosis of breast cancer among African women living in sub-Saharan Africa. PLoS One. 2017;12(2):e0171024. https://doi.org/10.1371/ journal.pone.0171024

11. Wu S, Powers S, Zhu W, Hannun YA. Substantial contribution of extrinsic risk factors to cancer development. Nature. 2016;529(7584):43, https://doi.org/10.1038/ nature16166

12. Cho J, Choi EK, Kim SY, et al. Association between cancer stigma and depression among cancer survivors: A nationwide survey in Korea. Psychooncology. 2013;22(10):2372-8. https://doi.org/10.1002/pon.3302

13. Ajekigbe AT. Fear of mastectomy: the most common factor responsible for late presentation of carcinoma of the breast in Nigeria. Clin Oncol (R Coll Radiol). 1991;3(2):78-80. https://doi.org/10.1016/S0936-6555(05)81167-7

14. Binka C, Nyarko SH, Awusabo-Asare K, Doku DT. 'I always tried to forget about the condition and pretend I was healed': Coping with cervical cancer in rural Ghana. BMC Palliative Care. 2018;17(1):24. https://doi.org/10.1186/s12904-018-0277-5

15. Ramanakumar AV, Balakrishna Y, Ramarao G. Coping mechanisms among longterm survivors of breast and cervical cancers in Mumbai, India. Asian Pac J Cancer Prev. 2005;6(2):189-94.

16. Adoga AA, Kokong DD, Silas OA, Mgbachi CJ. Follow up of Patients with Head and Neck Cancers in Jos, North-Central Nigeria. Ann Otolaryngol Rhinol. 2016;3(8):1125.

17. Espina C, McKenzie F, dos-Santos-Silva I. Delayed presentation and diagnosis of breast cancer in African women: A systematic review. Ann Epidemiol. 2017;27(10):659-71. https://doi.org/10.1016/j.annepidem.2017.09.007

18. Ankrah EM. The impact of HIV/AIDS on the family and other significant relationships: The African clan revisited. AIDS Care. 1993;5(1):5-22. https://doi. org/10.1080/09540129308258580

19. Hyacinth $\mathrm{HI}$, Adekeye OA, Ibeh JN, Osoba T. Cervical cancer and pap smear awareness and utilization of pap smear test among Federal civil servants in North Central Nigeria. PLoS One. 2012;7(10):e46583. https://doi.org/10.1371/journal. pone. 0046583

20. Getahun F, Mazengia F, Abuhay M, Birhanu Z. Comprehensive knowledge about cervical cancer is low among women in Northwest Ethiopia. BMC Cancer. 2013;13(1):2. https://doi.org/10.1186/1471-2407-13-2 